\title{
Assessment of Knowledge, Attitude and Practice of Adverse Drug Reaction Reporting Among Healthcare Workers in Selected Health Facilities in Abuja
}

\author{
Abubakar Mustapha Danraka ${ }^{1}$, Fatima Salisu Usman ${ }^{2}$, and Godspower Onavbavba ${ }^{1 *}$ \\ 1.National Institute for Pharmaceutical Research and Development, Idu, Abuja, Nigeria \\ 2.National Hospital Abuja, Plot 132 Central Business District (Phase II) Abuja
}

\begin{abstract}
Background: In recent years, deaths due to adverse drug reaction (ADR) have been on the increase. In order to reduce the untoward effects and to prevent deaths, reporting of ADR remains the cornerstone in improving patients safe use of drugs. Aim: This study aimed at assessing knowledge, attitude and practice of adverse drug reaction reporting amongst Medical Doctors, Pharmacists, and Nurses in selected health facilities within Abuja, Nigeria.Methods: A cross-sectional descriptive study was undertaken using questionnaire to assess knowledge attitude, and practice of reporting adverse drug reaction among the categories of healthcare workers included in the study.Results: The findings from the study showed that $99 \%$ of the study participants had knowledge about the standard definition of pharmacovigilance, majority of the study participants $(58.7 \%)$ indicated that ADR reporting should be made mandatory, more than two third of the study participants $(67 \%)$ had encountered cases of ADR in their practice, only a quarter of the participants $(26 \%)$ had reported cases of adverse drug reaction. Conclusion: This study revealed that almost of the study participants were aware of ADR, they had sound knowledge and positive attitude towards ADR reporting but unfortunately the practice of reporting was low among healthcare professionals included for this study.
\end{abstract}

Keywords: Pharmacovigilance, Adverse Drug Reaction, Knowledge, Attitude, Practice, Yellow Form

DOI: $10.7176 / \mathrm{JBAH} / 11-8-05$

Publication date: April $30^{\text {th }} 2021$

\section{BACKGROUND}

A drug is defined as a substance or combination of substances presented as having properties for treating or preventing diseases in humans and animals (Goldman, et al., 2015). Drugs can sometime also produce undesirable effects besides desired pharmacological effects. These effects not related pharmacological actions of the drug are referred to as Adverse Drug Reactions (ADR) (Duarte, et al., 2015). Depending on the severity, ADRs can cause hospitalization or death. The International Conference on Harmonization (ICH) guidelines on Good Clinical Practice (GCP) defined ADR as a response to a drug that is noxious and unintended and occurs at doses normally used in human for prophylaxis, diagnosis or treatment of diseases, or for modification of physiological function (Abdel-Lateef and Abdel-Wahab, 2015). Adverse drug reaction is a global problem of major concern. It affects both children and adult with varying degrees, causing both morbidity and mortality. Adverse drug reaction reporting also known as "pharmacovigilance", is the science dedicated to the study of safety of drugs, thus generating knowledge on the harmful effects of drugs both at the individual and population level so as to achieve safer use of drugs (Ohaju and Iribhogbe, 2010).

In recent years, deaths due to ADRs have increased (Tahani, et al., 1998). A study conducted by Abubakar, et al. (2014) observed that $5 \%$ to $10 \%$ of patients were admitted to hospitals as a consequence of ADR. In several studies, the frequency was estimated to be $20 \%$ of all cases admitted to the geriatric department as well as in the internal medicine department. A study conducted by Lazrou, et al., (1998) concluded that incidences of serious ADRs reported were $6.7 \%$ and fatal ADRs were $0.32 \%$ of hospitalized patients. Proper monitoring of ADR is therefore a necessity for healthcare professionals.

In Nigeria, healthcare professionals including medical doctors, nurses and pharmacists can report an ADR by filling the pharmacovigilance yellow form. Although several studies have evaluated the knowledge, attitude and practice of reporting adverse drug reaction among the healthcare professionals in Nigeria (Oshikoya and Awobusuyi, 2009; Fadare et al., 2011; Ogundele et al., 2012; Adedeji et al., 2013), no study has however been conducted in the Federal Capital Territory to include different healthcare professionals across different hospitals. It is a known fact that information regarding adverse drug reaction changes on a daily basis, hence the need for constant updating of the knowledge of healthcare workers in this area. It is against this backdrop that this study aimed at assessing, knowledge, attitude, and practice of ADR reporting amongst Medical Doctors, Pharmacists, and Nurses in selected health facilities within Abuja 


\section{METHODS}

\section{Study Setting}

This study was conducted in three hospitals in Abuja Municipal area council (AMAC), in the Federal Capital Territory Abuja. These hospitals are National Hospital Abuja, Wuse General Hospital and Asokoro District Hospital.

National Hospital Abuja is one of the major tertiary healthcare facilities that provides medical services to about ten million people (Alkali and Akano, 2013). The hospital also runs a postgraduate training to resident doctors and internship training to pharmacy interns and other profession in the health sector. The major departments in National Hospital Abuja include Pediatrics, Gynecology and Obstetrics, Surgery, Oncology, Internal Medicine and the National Trauma Centre.

Asokoro general hospital and Wuse general hospital are both located in the heart of the Federal Capital Territory. They provide effective and affordable healthcare services. Their services cover both urban population and the rural areas surrounding the hospitals. They also serve as a referral centre and provide wide range of technical and administrative support and training.

\section{Study Design}

A well structured, self-administered questionnaire was developed. The questionnaire was adapted from a similar study that investigated the knowledge, attitude and practice of ADR reporting among physicians in Nigeria (Fadare, 2011).

The questionnaire was designed to capture the following information; demographics data as well as knowledge, attitude and practice of the respondents towards ADR. The questionnaire was finalized after a series of revisions by taking into consideration the valuable comments from colleagues and advisors.

\section{Sample Population}

The population consists of National Hospital Abuja having 308 medical doctors, 652 nurses, and 53 pharmacists, Wuse General Hospital having 109 medical doctors, 208 nurses, and 26 pharmacists, and Asokokoro District Hospital having 100 medical doctors, 260 nurses and 45 pharmacists. These information from the three hospitals were all gotten from the office of the directorate of administration.

\section{Inclusion and Exclusion Criteria}

Doctors, nurses and pharmacists across all cadres in the three hospitals were included. Other healthcare professionals like medical laboratory scientists, radiographers and physiotherapists were excluded from the study. Sample Size

There were total number of 1851 Doctors, Pharmacists, and Nurses in the three health facilities used for this study. The sample size was therefore calculated using Yamane, (1973) Formula which is stated below.

$$
\mathrm{n}=\frac{N}{1+N(e)^{2}}
$$

Where:

$\mathrm{n}=$ corrected sample size,

$\mathrm{N}=$ population size (1851),

$\mathrm{e}=$ Margin of error $(\mathrm{MoE}), \mathrm{e}=0.05$.

$$
\begin{aligned}
& \mathrm{n}=\frac{1851}{1+1850(0.05)^{2}} \\
& \mathrm{n}=393.62
\end{aligned}
$$

The calculated sample size was rounded up to 500 so as to account for non-responses.

\section{Data Analysis}

Information from the returned questionnaires were coded and entered into Statistical Package for the Social Sciences (SPSS) version 20, univariate analysis was undertaken to yield descriptive statistics.

\section{Ethical Consideration}

Ethical Approval was obtained from the Health Research Ethics Committee of the Federal Capital Territory and the Health Research Ethics Committee of National Hospital Abuja.

\section{RESULTS}

\section{Demography}

Out of the 500 questionnaires that were administered, a total number of 387 were completed and returned, thereby giving a response rate of $77.4 \%$. Majority of the study participants were nurses $(58.7 \%)$, two third of the participants were females $(66.2 \%)$, three quarter of the study participants were married $(74.0 \%)$, and a third of the study participants had between 6 and 10 years working experience. Further details on socio-demographic characteristics are presented in table 1 below. 
Table 1: Demography

\begin{tabular}{ll}
\hline Variables & Frequency (\%) \\
\hline Gender & $132(33.8)$ \\
Male & $259(66.2)$ \\
Female & \\
Age & $166(51.7)$ \\
$18-35$ & $113(35.2)$ \\
$36-45$ & $42(13.1)$ \\
$46-65$ & $123(31.8)$ \\
Profession & $227(58.7)$ \\
Doctor & $37(9.6)$ \\
Nurse & \\
Pharmacist & $94(24.2)$ \\
Marital status & $287(74.0)$ \\
Single & $2(0.5)$ \\
Married & $5(1.3)$ \\
Divorced & \\
Widowed & $89(24.3)$ \\
Years of Experience & $127(34.6)$ \\
$1-5$ & $71(19.8)$ \\
$6-10$ & $36(9.8)$ \\
$11-15$ & $44(12.0)$ \\
$16-20$ & Above 20 years
\end{tabular}

Knowledge of Pharmacovigilance and Adverse Drug Reaction Reporting (ADR)

Almost all the study participants $(99.0 \%)$ knew the standard definition of "pharmacovigilance". A strong majority of the study participants $(92.1 \%)$ indicated that not all drugs in the market are safe, and considerable proportion of the study participants $(84.8 \%)$ indicated that the act of reporting ADR is their professional obligation. Further details relating to knowledge of pharmacovigilance and ADR are presented in table 2 below.

Table 2: Knowledge of Pharmacovigilance

\begin{tabular}{|c|c|c|c|}
\hline Variable & Yes & No & Not sure \\
\hline $\begin{array}{l}\text { The word "Pharmacovigilance" is defined as the science of } \\
\text { detecting, assessing, understanding and preventing adverse drug } \\
\text { reaction (ADR). }\end{array}$ & $385(99.0)$ & - & $4(1.0)$ \\
\hline $\begin{array}{l}\text { The most important purpose of pharmacovigilance is to assess safety } \\
\text { of drugs and identify previously unrecognized ADRs. }\end{array}$ & $381(97.7)$ & $2(0.5)$ & $7(1.8)$ \\
\hline Do you think that ADR reporting is professional obligation for you? & $330(84.8)$ & $15(3.9)$ & $44(11.3)$ \\
\hline Are you aware of any drug that has been banned from use? & $319(84.4)$ & $15(3$. & 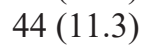 \\
\hline Do you believe that all drugs available in the market are safe? & $10(2.6)$ & $359(92.1)$ & $21(5.4)$ \\
\hline Is there a pharmacovigilance centre in your facility? & $162(41.3)$ & $50(12.8)$ & $180(45.9)$ \\
\hline $\begin{array}{l}\text { Do you know about the "Yellow form" for reporting adverse drug } \\
\text { reaction? }\end{array}$ & $244(62.6)$ & $116(29.7)$ & $30(7.7)$ \\
\hline $\begin{array}{l}\text { If response to B7 above is "yes", then, is the yellow form available in } \\
\text { your facility? }\end{array}$ & $113(35.5)$ & $31(9.7)$ & $176(55.0)$ \\
\hline $\begin{array}{l}\text { Do you know that you can get the Pharmacovigilance yellow form } \\
\text { from NAFDAC website online, fill and submit? }\end{array}$ & $124(32.0)$ & $170(43.9)$ & $93(24.0)$ \\
\hline $\begin{array}{l}\text { Are you aware that there is a National Pharmacovigilance Centre in } \\
\text { NAFDAC? }\end{array}$ & $265(68.8)$ & $68(17.7)$ & $52(13.5)$ \\
\hline $\begin{array}{l}\text { Do you think the ADR reporting and monitoring system will benefit } \\
\text { the patient? }\end{array}$ & $382(97.7)$ & - & $9(2.3)$ \\
\hline
\end{tabular}

Attitude Towards Pharmacovigilance and ADR Reporting

Almost all the study participants (99.8\%) indicated that reporting ADR is necessary, three quarter of the sample (74.5\%) indicated the need for confidentiality to be maintained while reporting ADR. Half of the study participants (49.1\%) agreed that ADRs are not adequately reported presently, whilst $60 \%$ of the participants indicated that the National Agency for Food and Drug Administration and Control (NAFDAC) has not created enough awareness and training regarding pharmacovigilance and ADR reporting. Other relevant details relating to attitude towards pharmacovigilance are presented in table 3 below. 
Table 3: Attitude Towards Pharmacovigilance

\begin{tabular}{llllll}
\hline Variable & $\begin{array}{l}\text { Strongly } \\
\text { Agree }\end{array}$ & Agree & Neutral & Disagree & $\begin{array}{l}\text { Strongly } \\
\text { Disagree }\end{array}$ \\
\hline $\begin{array}{l}\text { Reporting ADR is necessary. } \\
\text { ADR reporting is voluntary but } \\
\text { should be made mandatory. }\end{array}$ & $\begin{array}{l}325(83.8) \\
227(58.7)\end{array}$ & $\begin{array}{l}62(16.0) \\
121(31.3)\end{array}$ & $\begin{array}{l}1(0.3) \\
22(5.7)\end{array}$ & $15(3.9)$ & $2(0.5)$ \\
$\begin{array}{l}\text { Confidentiality should be maintained } \\
\text { while reporting ADR }\end{array}$ & $136(35.4)$ & $150(39.1)$ & $59(15.4)$ & $38(9.9)$ & $1(0.3)$ \\
$\begin{array}{l}\text { Legal problems are a concern while } \\
\text { reporting ADR. }\end{array}$ & $63(16.5)$ & $189(49.6)$ & $84(22.0)$ & $43(11.3)$ & $2(0.5)$ \\
$\begin{array}{l}\text { At present ADRs are adequately } \\
\text { reported and documented. }\end{array}$ & $43(11.1)$ & $65(16.8)$ & $89(23.0)$ & $188(48.6)$ & $2(0.5)$ \\
$\begin{array}{l}\text { NAFDAC has created sufficient } \\
\text { awareness on ADR reporting. }\end{array}$ & $15(3.9)$ & $47(12.2)$ & $90(23.4)$ & $229(59.5)$ & $4(1.0)$ \\
\hline
\end{tabular}

\section{Practice of Monitoring and Reporting ADR}

Findings from this study indicated that more than three quarter of the participants $(78.5 \%)$ had never filled the yellow form, less than a quarter of the participants $(20.7 \%)$ had filled the yellow form $\leq 20$ times, whilst only $8 \%$ of them had filled the form $>20$ times. Slightly above a third of the sample $(78.5 \%)$ indicated that they normally fill the yellow form after an ADR encounter in $\leq 1$ week, less than a quarter of the sample (20.5\%) indicated that they normally report ADR event $\leq 3$ months after encounter, and 9.6\% indicated that they report ADR $>3$ months after encounter. Further details relating to practice of monitoring and reporting ADR are presented in table 4 below.

Table 4: Practice of Monitoring and Reporting ADR

\begin{tabular}{llll}
\hline Variable & Yes & No & Not Sure \\
\hline $\begin{array}{l}\text { Have you ever experienced adverse drug reaction in your } \\
\text { patient during your professional practice? }\end{array}$ & $265(68.7)$ & $12(3.1)$ & $109(28.2)$ \\
$\begin{array}{l}\text { Have you ever reported an adverse drug reaction to the } \\
\text { pharmacovigilance unit? }\end{array}$ & $103(26.8)$ & $277(71.9)$ & $5(1.3)$ \\
$\begin{array}{l}\text { Only pharmacists, nurses and doctors are responsible for } \\
\text { reporting adverse drug reaction. }\end{array}$ & $69(17.9)$ & $80(20.8)$ & $236(61.3)$ \\
$\begin{array}{l}\text { After submitting your report, did you get any feedback from } \\
\text { the centre where you submitted? }\end{array}$ & $26(16.0)$ & $91(56.2)$ & $45(27.8)$ \\
$\begin{array}{l}\text { If yes to the above question, were you comfortable with the } \\
\text { feedback received? }\end{array}$ & $16(15.7)$ & $53(52.0)$ & $33(32.4)$ \\
$\begin{array}{l}\text { Have you ever shared information about ADRs your patient } \\
\text { encountered with anyone? }\end{array}$ & $233(63.3)$ & $121(32.9)$ & $14(3.8)$ \\
$\begin{array}{l}\text { Have you ever been trained on how to report adverse drug } \\
\text { reaction? }\end{array}$ & $83(21.3)$ & $291(74.8)$ & $15(3.9)$ \\
$\begin{array}{l}\text { Do you feel that proper training should be provided to } \\
\text { healthcare professionals on ADR reporting? }\end{array}$ & $364(93.8)$ & $8(2.1)$ & $16(4.1)$ \\
\hline
\end{tabular}

\section{DISCUSSION}

Findings from this study revealed that almost all the respondents knew the meaning of the word "pharmacovigilance" and they also understood the purpose and concept of pharmacovigilance, suggesting that pharmacovigilance was not new to them. Drugs can produce both desirable and undesirable effect and it was observed that a large proportion of the study participants were aware that not all drugs in the market are safe as some may result to serious adverse reaction to some persons. Depending on severity, adverse drug reaction can cause hospitalization and even death (van der Hooft et al., 2006).

Interestingly, a strong majority of the study participants indicated ADR reporting as part of their professional obligation and job description. This is however in contrast with an Ethiopian study where participants in that study indicated that ADR reporting is solely the responsibility of pharmaceutical companies (Abu et al., 2015). Available evidence suggest that healthcare workers have critical role to play regarding ADR reporting (Hanafi et al., 2012).

Information gathered during preclinical and clinical trial are not enough to conclude safety of a particular drug, hence the need for continuous assessment and evaluation of drugs in the market. However, report shows that it is almost impossible to detect ADR from drugs which adverse drug reaction associated with them only occurs after prolong usage (Goldman et al., 1995). A third of the study participants were aware that yellow form exists for reporting ADR, this is in contrast with previous findings among Nigerian doctors where low awareness about procedure for reporting ADR was reported (Oshikoya and Awobusuyi, 2009; Fadare et al., 2011; 
Ogundele et al., 2012; Adedeji et al., 2013). Of those that claimed awareness of what "yellow form" is about, majority of them indicated that the form is not readily available for them to use. The non-availability of the form can limit their intentions to report cases of ADR. Also, more than two third of the study participants were aware of the existence of National Pharmacovigilance Centre which is domiciled in NAFDAC. This is in line with a previous Nigerian study (Joseph et al., 2011), but dissimilar with a study conducted in Cyprus (Granas et al., 2007) where majority of respondents reported ignorance of the National body that collates ADR cases in that country.

Findings from this study further indicates that only a third of the study participants were aware that "yellow form" for the reporting of ADR can be filled and submitted online to NAFDAC, suggesting the need for more awareness to be created among healthcare personnel in this regard. Creating this awareness will provide opportunity for healthcare personnel practicing in healthcare facilities where yellow forms are not readily available to be able to report cases of ADR directly to NAFDAC without delay. Also, only slightly above a third of the participants were aware of the existence of pharmacovigilance centre in their facilities, suggesting that majority of the participants may likely not report a case of ADR if they come across one.

Participants in this study demonstrated a positive attitude towards reporting of ADR as almost all the participants indicated that reporting of ADR is necessary and strongly supported the need for ADR reporting to be made mandatory. These findings also corroborate previous findings (Green et al., 2001). Majority of the study participants indicated that cases of ADRs are not adequately reported, and they also indicated that NAFDAC has not created sufficient awareness regarding ADR reporting. These findings therefore suggest the need for NAFDAC to increase awareness among healthcare workers on the need for reporting ADR.

A third of the participants in this study seems to have had experience with patients affected with ADR in the course of carrying out their professional obligation, however, only a quarter of them had reported ADR to pharmacovigilance unit. These findings suggest low interest in the reporting of ADR event by healthcare workers. Although those that had filled the yellow form more than 20 times were relatively few, however, majority of those that had filled the yellow form usually take $\leq 1$ week to do so. These findings suggest high level of enthusiasm among those that are already carrying out pharmacovigilance activities in their facilities. However, majority of those that had submitted yellow form to pharmacovigilance unit indicated that they did not receive any feedback after submission. This is an area that NAFDAC can improve upon so as to further encourage those interested in reporting ADR events, as not receiving feedback can reduce the morale of those that had previously reported cases of ADRs.

\section{CONCLUSION}

This study gives pertinent information regarding knowledge, attitude and practice of reporting adverse drug reaction and some factors that pose as barriers to reporting. The study revealed that even though majority of health professionals have positive attitude towards ADR reporting, reporting among health professionals was low. This could be due to low level of training and creation of awareness among health professionals towards ADR reporting.

Awareness creation program on ADR reporting system, need to be designed for healthcare professionals by relevant bodies like NAFDAC. ADR reporting system need to be introduced and given emphasis at the higher institution training. Also, establishing strong feedback and increasing options of reporting would improve the reporting system.

It is recommended that yellow forms be made available in all healthcare facilities, and continuous training of healthcare workers on pharmacovigilance be given priority attention. Furthermore, a reward system for healthcare workers on ADR reporting can go a long in encouraging the reporting of ADR events.

\section{REFERENCES}

Abdel-Lateef MM and Abdel-Wahab BA (2015). Knowledge and awareness of adverse drug reaction, and pharmacovigilance practices, among Healthcare Professionals in Al-Madinah Al-Munawwarah, Kingdom of Saudi Arabia. Saudi Pharmacy Journal 23(2): 154-161.

Abu FR, Farha O, Suyagh M (2015). Knowledge, Practice and Attitude of Healthcare Professionals towards Pharmacovigilance and Adverse Drug Reaction Reporting Process. Ethiopia Pharmacy Journal 23: 147-153.

Adedeji WA, Ibraheem WA, Fehintola FA (2013). Attitude and practice of doctors toward adverse drug reactions (ADRs) reporting in a Nigerian tertiary health facility. Annals of Ibadan postgraduate medicine. 11(2):77-80.

Alkali N, and Akano A (2013). Stroke risk factors, subtypes and 30-day case fatality in Abuja, Nigeria. Journal of Nigerian Medical Association 54: 129-135.

Fadare JO, Enwere OO, Afolabi AO, Chedi BA, Musa A (2011). Knowledge, attitude and practice of adverse drug reaction reporting among healthcare workers in a tertiary centre in Northern Nigeria. Tropical Journal of Pharmaceutical Research. 10(3): 235-242 
Goldman SA, Kennedy OL and Liebermann R (1995). Clinical Therapeutics and Recognition of Drug-induced Disease. Journal of Pharmacology and Pharmacotherapy 10(5): 345-355.

Granas AG, Stanberg H and Torkamandi H (2007). Knowledge, Practice and Attitude of Pharmacists towards Pharmacovigilance and Adverse Drug Reaction Reporting Process in Cyprus. Pharmacoepidemiology Drug Safety 16(2): 429-434.

Green CF, Mottram DR, Rowe PH, Pirmohamed M (2001) Attitudes and knowledge of hospital pharmacists to adverse drug reaction reporting. British journal of clinical pharmacology. 51(1):81-6.

Hanafi S and Juvadi M (2012). Knowledge, Practice and Attitude of Nurses towards Pharmacovigilance and Adverse Drug Reaction Reporting Process. Iran Journal of Nurses and Midwifery 17: 21-25.

Joseph O, Fadare E. Okezie O, Afolabi AO, Chedi BAZ and Musa A (2011). Knowledge, Attitude and Practice of Adverse Drug Reaction Reporting among Healthcare Workers in a Tertiary Centre in Northern Nigeria. Tropical Journal of Pharmaceutical Research. 10(3): 235-242.

Ogundele SO, Dawodu CO, Ogunleye OO (2012). Adverse drug reaction reporting among healthcare workers at a Nigerian Tertiary Hospital: a comparative cross-sectional survey of health-care professionals. Glo. Res. J. Med. Sci, 2(2):32-37

Ohaju JO and Iribhogbe OI (2010). Extent of Pharmacovigilance among Resident Doctors in Edo and Lagos State of Nigeria. Pharmacoepidemiology Drug Safety Journal 16(3) 19:24.

Oshikoya KA, Awobusuyi JO (2009). Perceptions of doctors to adverse drug reaction reporting in a teaching hospital in Lagos, Nigeria. BMC Clinical Pharmacology, 9:14.

Tahani MA, Anas H, Hassan M, Dalal S and Naseem A (1998). Adverse Drug Reactions and Pharmacovigilance: A Narrative Mini-Review of Relevant Literature. Journal of Advances in Medical Pharmaceutical Sciences 11(2): 67-81.

van der Hooft CS, Sturkenboom MC, van Grootheest K, Kingma HJ, Stricker BH (2006). Adverse drug reactionrelated hospitalisations. Drug safety. 2006 Feb;29(2):161-8.

Yamane, T., 1973. Statistics: An introductory analysis. 2nd ed. Tokyo: Harper and Row, New York, Evanston and London and John Weather Hill, Inc. pp. 915-919. 